\title{
Aerosol delivery from spacers in wheezy infants: a daily life study
}

\author{
H.M. Janssens*, E.M.E.W. Heijnen*, V.M. de Jong*, W.C.J. Hop**, W.P.J. Holland', \\ J.C. de Jongste*, H.A.W.M. Tiddens*
}

\begin{abstract}
Aerosol delivery from spacers in wheezy infants: a daily life study. H.M. Janssens, E.M.E.W. Heijnen, V.M. de Jong, W.C.J. Hop, W.P.J. Holland, J.C. de Jongste, H.A.W.M. Tiddens. C ERS Journals Ltd 2000.

ABSTRACT: The aims of this study were to assess and compare dose delivery and dose variability of pressurized metered dose inhalers (pMDI)/spacers in wheezy infants in daily life and to investigate factors influencing aerosol delivery.

In an open randomized crossover study in 25 wheezy infants aged 5-26 months, a metal spacer (Nebuchamber $($ ) ), a detergent coated (DC) and a non-detergent coated (nonDC) plastic spacer (Babyhaler $($ ) ) were tested at home for 7 days each. Budesonide $(200 \mu \mathrm{g}$ b.i.d.) was administered via a Nebuchamber or fluticasone $(125 \mu \mathrm{g}$ b.i.d.) via a Babyhaler. Aerosol was trapped in filters, positioned between the spacer and face mask. Cooperation was scored on diary cards. Electrostatic charge (ESC) of the spacers was measured. Evaluations of the administration technique were made from video recordings.

Median (range) dose delivery of the filters expressed as per cent (\%) of nominal dose, was 34\% (3-59), 23\% (1-49), and 41\% (12-55) for the Nebuchamber, nonDCBabyhaler, and DC-Babyhaler respectively. Considerable dose variability was found, median (range) within-subject dose variability, expressed as coefficient of variation, for the Nebuchamber $(49 \%(15-249))$ was significantly higher when compared with both nonDC- (36\% (12-325)) and DC-Babyhalers (27\% (10-122)), for which dose variabilities were similar.

Detergent coating was effective to reduce electrostatic charge, and to increase dose delivery, but had no effect on dose variability. Bad cooperation was an important cause for high dose variability for all spacers $(\mathrm{r}=\mathbf{0 . 5}-\mathbf{0 . 6}, \mathrm{p}<\mathbf{0 . 0 2})$. Many mistakes were made during the administration procedure.
\end{abstract}

Eur Respir J 2000; 16: 850-856.

\begin{abstract}
*Dept of Paediatrics, div. Paediatric Respiratory Medicine, **Dept of Biostatistics, Central Instrumentation Dept, Sophia Children's Hospital, Erasmus Medical Centre, Rotterdam, the Netherlands.

Correspondence: H.M. Janssens, Dept of Paediatric Respiratory Medicine, Sophia Children's Hospital, PO Box 2060, 3000 CB Rotterdam, the Netherlands. Fax: 31 104636772
\end{abstract}

\section{Keywords: Aerosol}

electrostatic charge

handling

infants

spacer

Received: June 151999

Accepted after revision August 212000

This study was supported by a grant from AstraZeneca, the Netherlands.
Spacers were introduced to facilitate inhalation of therapeutic aerosols from pressurized metered dose inhalers (pMDI), being especially useful for the treatment of asthma in young children. Spacers are widely used, but little is known about their dose delivery, and dose variability in daily life use. This information is important, since it allows the clinician to select the proper dose and device for a patient. The dose delivered from a spacer can be unpredictable and depends on a number of patient and device-related factors [1-4]. Considerable between-subject variability in aerosol delivery from spacers has been found in a laboratory setting $[1,5]$. However, these previous studies did not adequately represent the situation in daily life.

In a previous study, the authors showed that there is considerable dose-to-dose (or within-subject) variability from metal as well as plastic spacers when studied at the homes of children aged 17 months- 8 yrs [6]. In children aged $<4$ yrs, dose variability was inversely related to age. However, this study resulted in a number of unanswered questions, which prompted further research. Firstly, the number of children aged $<2$ yrs was too small for the results to be conclusive for this age group. Young children of this age form a special treatment group, as factors such as cooperation, acceptance and the use of a face mask may determine the success or failure of inhalation therapy. The relevance of these factors on aerosol delivery from pMDI/ spacers in daily life has not been studied previously. Additionally, many mistakes in the administration technique were observed or suspected but it was not systematically evaluated. Secondly, it was not clear whether the results of the metal and plastic spacers could be interpreted as differences in spacer design or due to the presence or absence of electrostatic charge (ESC). Various studies have shown that plastic spacers can get electrostatically charged, which decreases drug delivery [7, 8]. ESC can be minimized by coating the plastic spacer with a household detergent $[8,9]$. ESC is absent in a metal spacer. Furthermore, the authors wanted to repeat the study using a different $\mathrm{pMDI} / \mathrm{spacer}$ combination, for it has been shown that each $\mathrm{pMDI} / \mathrm{spacer}$ combination behaves differently [2]. Therefore, a study to assess and compare aerosol delivery for a metal spacer (Nebuchamber $\mathbb{R}$, AstraZeneca, Lund, Sweden) [5] with budesonide pMDI (Pulmicort $\AA$, AstraZeneca) and for a DC and nonDC plastic spacer (Babyhalerß, Glaxo Wellcome, London, UK) [10] with fluticasone pMDI (Flixotide( $\mathrm{R}$, Glaxo Wellcome), in wheezy infants aged $0-2$ yrs in a daily life setting, was designed. Various factors, such as cooperation and administration technique, that might affect dose delivery and dose variability in daily life were studied. 


\section{Materials and methods}

\section{Study population}

Twenty-six children aged 5-26 months with recurrent wheeze requiring daily inhalation therapy were recruited from the outpatient clinic of the Sophia Children's Hospital (Rotterdam, the Netherlands), the Merwede Hospital (Dordrecht, the Netherlands) and from a general practitioner population (Brielle, the Netherlands). None of the subjects suffered from other disorders that could affect cooperation or lung function. Written informed consent was obtained from all the parents. The study was approved by the local ethics committee.

\section{Study design}

In a four-week randomized cross-over study, the children were visited on five occasions. At the first and second home visit standardized instructions were given on the use of the spacers. During the first week, the run-in week, the children had to practice with both types of spacers. Over the next three weeks a metal spacer, a nonDC and DC plastic spacer were tested in a randomized order, twice a day for 1 week each. Aerosol delivery was assessed by means of filters, placed between the face mask and spacer. The parents completed a diary card on symptom score and cooperation score during the administration procedure twice daily. ESC of the plastic spacers was measured before and after one week of use. The administration procedure was recorded on video twice, once, at the end of the week of using the metal spacer and once after using one of the plastic spacers.

\section{Spacers and pMDI's}

The spacers tested were the metal Nebuchamber $\mathbb{R}$ ( 250 $\mathrm{mL})$ and the polycarbonate Babyhaler $(350 \mathrm{~mL})$, both with their original face masks. The Babyhaler was used with and without detergent coating, to evaluate the influence of ESC. All spacers were washed the day before they were allocated to the children. The Nebuchamber and the nonDC Babyhaler were washed in soapy water with normal household detergent, rinsed thoroughly with warm water and drip dried according to the instructions for use provided by the manufacturers. The DC Babyhaler was also washed in soapy water but not rinsed with water, and left to drip-dry [9]. All the subjects received a clean spacer each week.

Budesonide pMDI $200 \mu \mathrm{g} \cdot \operatorname{dose}^{-1}$ (Pulmicort $\AA$, AstraZeneca, Lund, Sweden) was used as the study medication for the Nebuchamber. Fluticasone pMDI $125 \mu \mathrm{g} \cdot \mathrm{dose}^{-1}$ (Flixotide ( ), Glaxo Wellcome, London, UK) was used for the Babyhaler. Each child received new pMDI's. The first ten actuations of a new pMDI were wasted, to avoid variable doses $[11,12]$.

At the end of each week, spacers were rinsed with ethanol to quantify the amount of drug retained in the spacer for evaluation of the effect of detergent coating.

\section{Filters and filter analysis}

Aerosol delivery was measured by means of a filter (Vital Signs Inc., Totowa, NJ, USA), inserted between the face mask and spacer. The filter has been shown to retain
$>99 \%$ of the drug delivered from a spacer [5]. The filter added a dead space of $20 \mathrm{~mL}$ to the spacer. The pressure drop over the filter is $230 \mathrm{~Pa}$ at $60 \mathrm{~L} \cdot \mathrm{min}^{-1}$ [5], which is approximately one-fifth of the airway resistance of an infant [13]. A preliminary study showed that the filter did not significantly alter the tidal volume and respiratory rate in nine children aged 10-24 months (data not shown). For each spacer a maximum of 14 filters was obtained per child (i.e. two filters per day). Budesonide and fluticasone on filters and spacers were quantified by a validated method with high-performance liquid chromatography (HPLC), using an ethanol:water (43:57) mobile phase and a Supelcosil LC-18 column $(5 \mathrm{~mm}$ particles, $5 \mathrm{~cm} \times 0.46$ $\mathrm{cm}$ (inner diameter)). The coefficient of variation of the method was $<3 \%$.

\section{Diary card}

To monitor symptoms and cooperation during the study period, parents filled out a diary card twice a day. The following items were scored: cough, wheeze, shortness of breath, and cooperation during the administration procedure. Each item was assigned a score of $0-3$. Score 0 for no symptoms or good cooperation, score 3 for severe symptoms or for struggling against the procedure. Total symptom score, with a maximum of 9 , was defined as the sum of the scores for the 3 items: cough, wheeze and shortness of breath. This symptom score was used to assess whether the different spacers were tested under similar conditions.

\section{Electrostatic charge}

To evaluate the effect of detergent coating, ESC on the inner surface of the nonDC-Babyhaler and DC-Babyhaler was measured during the home-visits immediately before and after 1 week of use with a custom made electrometer (Central Instrumentation Dept, Erasmus University, Rotterdam, the Netherlands). The electrometer consisted of a metal probe with a length of $12 \mathrm{~cm}$ connected to a high impedance voltmeter. To measure ESC the probe was positioned exactly in the middle of one-half of the spacer, using a wooden disc at the bottom of the probe, which fitted as a lid on the spacer half. The variability of this method of measurement was 5\%. Any ESC on the inner surface of the spacer induced a charge on the probe, which was shown on the display of the electrometer. The electrometer had been calibrated on a foil-coated Babyhaler with applied voltages. The measurements were performed in a standardized fashion. Both halves of the disconnected Babyhaler were measured separately. The measured voltage was used as a measure for ESC. The ESC of the entire spacer was calculated according to the formulas: $\mathrm{Q} 1+\mathrm{Q} 2=$ Vtotal $\left(\mathrm{C}_{1}+\mathrm{C}_{2}\right)$ and $\mathrm{Q} 1+\mathrm{Q}_{2}=\mathrm{C}_{1} \mathrm{~V}_{1}+$ $\mathrm{C} 2 \mathrm{~V} 2$ in which numbers 1 and 2 refer to the two separate spacer halves, $\mathrm{Q}$ is charge, $\mathrm{C}$ is capacitance of the spacer, $\mathrm{V}$ is measured voltage and Vtotal is voltage of the total spacer.

\section{Video}

The administration technique was recorded on video during 2 of the 5 home visits, for the Nebuchamber and the nonDC-Babyhaler or DC-Babyhaler after they were used for one week. After completion of the study all recordings 
were scored on administration technique according to a checklist with 10 items (table 1) in a binomial scale, by five experienced observers. Observers were trained on how to use the scoring system with an instruction video. The video recordings were scored in a randomized order. An item was considered correct if at least 3 observers had scored this item as correct.

Agreement between video observers was calculated as follows: for each child, all 10 items (table 1) were added by each observer per spacer to give a total score ranging from 0 (all items wrong) to 10 (all items correct). The agreement between each pair of observers regarding this score was assessed by calculation of the intra-class correlation coefficient. All pairwise coefficients were found to be $>0.72$ (mean: 0.84), indicating a good level of agreement between observers.

\section{Instruction of administration technique}

On the first visit the use of the pMDI/spacers with the filter was demonstrated. The study medication had to be administered twice daily, before regular maintenance therapy, which was continued during the study period. Before each administration a new filter was placed on the spacer by the parents. The face mask and the pMDI were attached to the spacer. Subsequently the pMDI/spacer was shaken for $10 \mathrm{~s}$ before placing the face mask on the child. The spacer was held in a horizontal position, while ensuring a close fit of the face mask, with the child in an upright position. Next, one puff of aerosol was actuated into the spacer. The child had to inhale for $30 \mathrm{~s}$ with quiet tidal breathing. Subsequently, the filter was removed from the spacer and both sides of the filter holder were sealed with tape. Each filter was labelled with a unique code. Finally, the filters were stored in a black plastic bag to protect the drug from destabilization by light. On the second visit the administration technique was demon-

Table 1. - Checklist for the administration technique

\begin{tabular}{lcc}
\hline \multirow{2}{*}{ Items } & \multicolumn{2}{c}{ Number (\%) scored correctly } \\
\cline { 2 - 3 } & Nebuchamber & Babyhaler \\
\hline $\begin{array}{l}\text { 1. Child sits upright } \\
\text { 2. pMDI is placed correctly } \\
\text { into the spacer }\end{array}$ & $20(91)$ & $22(92)$ \\
$\begin{array}{l}\text { 3. pMDI/spacer is shaken for } \\
\text { at least } 5 \mathrm{~s}\end{array}$ & $22(100)$ & $24(100)$ \\
$\begin{array}{l}\text { 4. Time between shaking and } \\
\text { actuating is <5 s? }\end{array}$ & $15(68)$ & $16(67)$ \\
$\begin{array}{l}\text { 5. Face mask is placed on face } \\
\text { before actuation of the puff }\end{array}$ & $19(86)$ & $18(75)$ \\
$\begin{array}{l}\text { 6. There is a close fit of the } \\
\text { face mask }\end{array}$ & $16(73)$ & $22(92)$ \\
$\begin{array}{l}\text { 7. One puff is actuated? } \\
\text { 8. Child breathes for } 30 \mathrm{~s} \\
\text { through the spacer }\end{array}$ & $20(91)$ & $23(96)$ \\
$\begin{array}{l}\text { 9. Child breathes quietly } \\
\text { through the spacer? }\end{array}$ & $10(46)$ & $14(58)$ \\
$\begin{array}{l}\text { 10. Face mask is held on face } \\
\text { during the } 30 \text { s? }\end{array}$ & $14(64)$ & $15(63)$ \\
\hline
\end{tabular}

pMDI: pressurized metered dose inhalers. Nebuchamber: $n=22$; Babyhaler: $n=24$. strated by the parent and child to the investigator and corrected where necessary.

\section{Statistical analysis}

Filter dose was calculated as the amount of aerosol deposited on the filter as a percentage of the nominal dose. Nominal dose for the budesonide pMDI was $200 \mu \mathrm{g}$ and for the fluticasone pMDI $125 \mu \mathrm{g}$. Dose delivery, was calculated as the mean filter dose of the 14 samples collected in one week for each child. The within-subject dose variability, expressed as coefficient of variation (CV), was calculated for each child and spacer. Drug retained in the spacer after one week use was expressed as a percentage of the total amount of drug administered in 1 week. Mean symptom score was defined as the average of the total symptom score recorded on the diary card during one week. Mean cooperation score was calculated for each child per spacer.

Consecutive actuations into an electric spacer may reduce ESC and subsequently increase the dose delivered [5]. Whether this "priming effect" was present during 1 week use, was investigated by plotting all the filter doses for each child against the 14 sample numbers and drawing individual regression lines through these data points. For each spacer the mean slope of the individual regression lines was calculated.

The Friedman test was used for overall comparisons between the various parameters investigated for the three spacers. If significance was present $(\mathrm{p}<0.05)$, pairwise comparisons were made with the Wilcoxon signed ranks test. The comparisons were carried out in triplicate: a) analysis of all available data, b) after excluding the samples where the child had not cooperated during the procedure (cooperation score 2 and 3), and c) after excluding the filters where filter dose was 0 . Correlations were investigated between dose delivery and within-subject dose variability versus age, mean cooperation score, and video score using Spearman's correlation coefficient (r). Dose delivery and dose variability of children who were using a Nebuchamber for maintenance therapy before study entry were compared with the dose delivery and dose variability of children who were using another spacer. There were only five children who used a Babyhaler before study entry, a number that was too small to reliably compare this group with those who used other spacers. Results are given as median (range) unless otherwise indicated.

\section{Results}

Of the 26 children included in the study, one child was excluded because the fluticasone pMDI had been used with the cap on, resulting in no drug on the filters. The remaining 25 children $(21$ male) form the study group of this report. Median age was 14 (5-26) months. The inhalation devices used before study entry were: Nebuchamber $(n=12)$, Babyhaler $(n=5)$, Aerochamber $(n=5)$ (Trudell Medicals, London, Ontario, Canada), nebulizer $(n=2)$, nebulizer+Nebuchamber $(n=1)$. A total of 319,326 and 325 filters were collected for the Nebuchamber, the nonDC-Babyhaler and the DC-Babyhaler respectively. 
Symptom scores were low and similar during the use of different spacers: median score was $0.2,0.1$, and 0.4 for the Nebuchamber, the nonDC-Babyhaler, and DC-Babyhaler respectively $(\mathrm{p}=0.99)$.

\section{Dose delivery}

Dose delivery, expressed as a percentage of the nominal dose, for all spacers is shown in figure 1. Median (range) dose delivery was $34 \%(3-59), 22 \%(1-49)$ and $41 \%(12-$ $55)$ for the Nebuchamber, the nonDC-Babyhaler, and DC-Babyhaler respectively. Median dose delivery for the Nebuchamber was significantly higher than for the nonDC-Babyhaler $(p=0.03)$ but lower than for the DCBabyhaler $(\mathrm{p}=0.005)$. The difference in dose delivery between nonDC-Babyhaler and DC-Babyhaler was highly significant $(\mathrm{p}<0.001)$. There was a positive correlation between the dose delivery of the Nebuchamber and the DC-Babyhaler $(r=0.5, p=0.01)$ and between the nonDCand DC-Babyhaler $(\mathrm{r}=0.5, \mathrm{p}=0.02)$. In other words, children with a low dose delivery in one spacer tended to have a low dose delivery in the other spacers too. This correlation was not significant between the Nebuchamber and the nonDC-Babyhaler $(\mathrm{r}=0.3, \mathrm{p}=0.1)$. No drug was found on the filter in $n=37(12 \%), n=20(6 \%)$ and $n=11$ (3\%) filters of the Nebuchamber, the nonDC-Babyhaler and DC-Babyhaler respectively. The conclusions as described above did not change when the filters without drug were excluded from the analysis. No significant priming effect was found for any of the three spacers. No significant correlation was found between age and dose delivery for any of the three spacers.

\section{Dose variability}

Dose variability, expressed as the within-subject coefficient of variation (CV), for each spacer is shown in figure 2. Median dose variability was 49\% (15-249), 36\% (12-325) and 27\% (10-122) for the Nebuchamber, the nonDC-Babyhaler, and DC-Babyhaler respectively. The dose variability for the Nebuchamber was significantly higher than the dose variability for the nonDC-Babyhaler

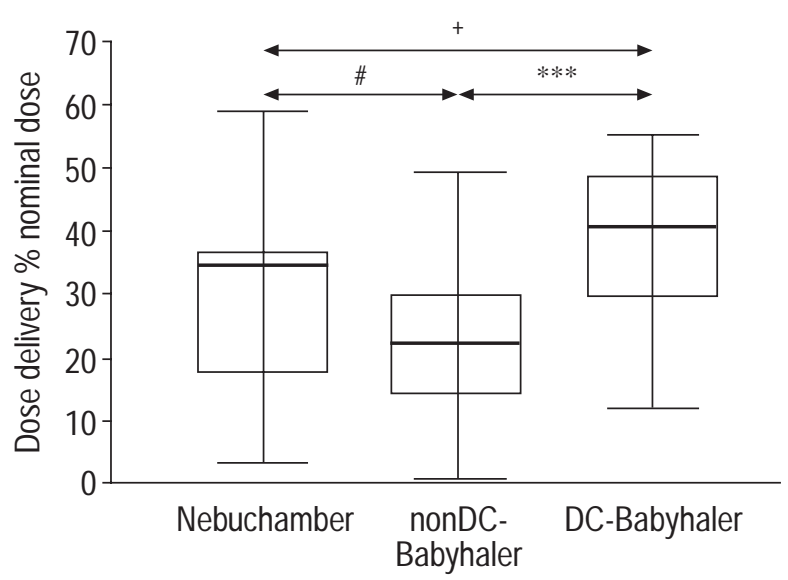

Fig. 1. - Boxplot of dose delivery, calculated from the mean dose on the filters as a percentage of nominal dose per child, for the Nebuchamber, non-detergent coated (nonDC) Babyhaler and the detergent coated (DC) Babyhaler. Whiskers represent largest and smallest observed value that is not outlier, box represents 25th and 75th percentiles, and bar represents median. ${ }^{\#}: \mathrm{p}=0.03 ;{ }^{* * *}: \mathrm{p}<0.001 ;{ }^{+}: \mathrm{p}=0.005$.

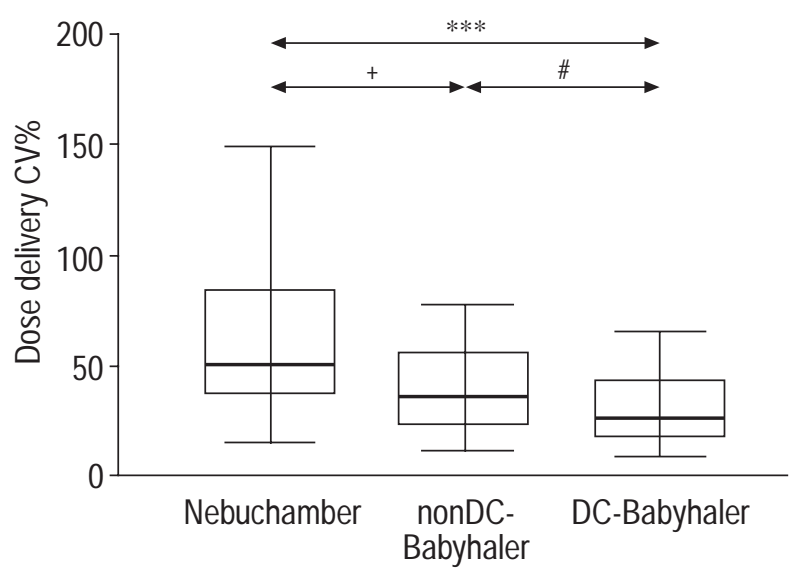

Fig. 2. - Boxplot of within-subject dose variability, expressed as coefficient of variation (CV\%) for the Nebuchamber, non-detergent coated (nonDC) Babyhaler and the detergent coated (DC) Babyhaler. ${ }^{+}$: $\mathrm{p}=0.025 ; * * *: \mathrm{p}<0.001 ;{ }^{\#}: \mathrm{p}=$ not significant.

and DC-Babyhalers. The dose variability for the nonDCBabyhaler and the DC-Babyhaler were not significantly different. There was a positive correlation between the dose variabilities of the Nebuchamber and the nonDCBabyhaler $(r=0.4, p=0.03)$ and between the nonDC-and DC-Babyhaler $(\mathrm{r}=0.6, \mathrm{p}=0.001)$, children with a high dose variability in one spacer, also tended to have a high dose variability in the other spacers. This correlation was not significant for the combination Nebuchamber versus DC-Babyhaler $(r=0.3, p=0.1)$. There was no significant correlation between dose variability and age. Differences in dose delivery and dose variability between children who used a Nebuchamber before study entry and children who used another spacer were not significant.

\section{Cooperation score}

Mean cooperation scores, obtained from the completed diary cards, were not significantly different between the three different spacers: median (range) was 0.7 (0-2.7), 0.4 $(0-2.3)$ and $0.6(0-2.3)$ for the Nebuchamber, nonDCBabyhaler and DC-Babyhaler, respectively. Bad cooperation during administration (score 2-3) was scored in $28 \%$, $19 \%$ and $22 \%$ of all scores for the Nebuchamber, the nonDC-Babyhaler and the DC-Babyhaler, respectively. The overall comparisons of the data were repeated after excluding the filter doses on which cooperation was scored 2 or 3 (bad cooperation). This did not affect the conclusions as described. A high (=bad) cooperation score led to a higher dose variability for all spacers (fig. 3) and a lower dose delivery for the Nebuchamber only $(\mathrm{r}=0.5$, $\mathrm{p}=0.009$ ).

\section{Electrostatic charge}

ESCbefore and ESCafter one week use for each spacer is shown for the nonDC-Babyhaler and DC-Babyhaler in figures $4 \mathrm{a}$ and $\mathrm{b}$ respectively. In both the nonDCBabyhaler and the DC-Babyhaler the ESC increased significantly during use for one week $(p<0.001)$. ESCbefore and ESCafter were significantly higher in the nonDC-Babyhaler compared with the DC-Babyhaler 


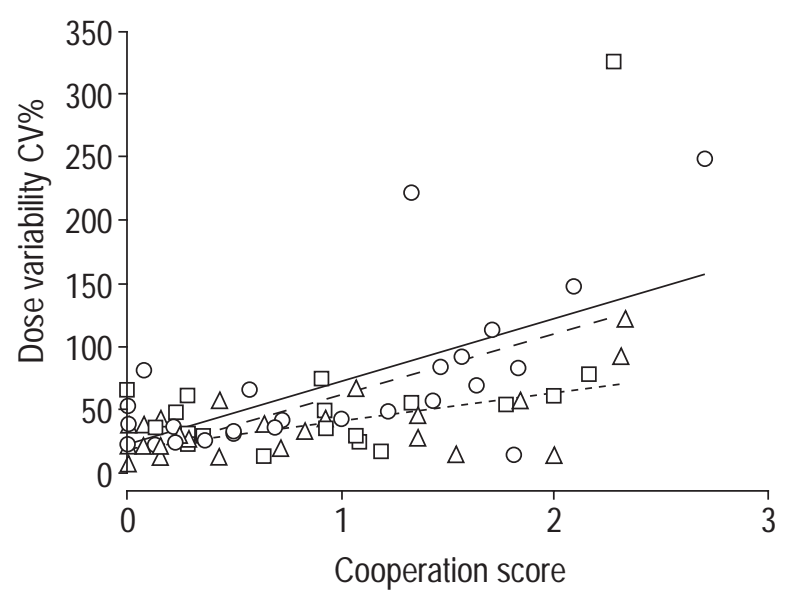

Fig. 3. - Scatterplot of within-subject dose variability (CV\%) versus mean cooperation score for the Nebuchamber, non-detergent coated Babyhaler and detergent coated Babyhaler. _ , *: Nebuchamber $(\mathrm{r}=0.6$, $\mathrm{p}=0.002) ;---$, $\square$ : non-detergent coated Babyhaler $(\mathrm{r}=0.5, \mathrm{p}=0.02) ; \cdots \cdots$, $\triangle$ : detergent coated Babyhaler $(\mathrm{r}=0.5, \mathrm{p}=0.009)$. Cooperation score: $0=$ good, $3=$ bad.

$(\mathrm{p}<0.001)$. ESCbefore was $0 \mathrm{~V}$ in only one $(4 \%)$ of the nonDC-Babyhalers, against $18(72 \%)$ of the DCBabyhalers. ESCafter was $0 \mathrm{~V}$ in none of the nonDCBabyhalers and in three (12\%) of the DC-Babyhalers.

Detergent coating significantly reduced the amount of drug retained in the spacer. This was 50\% (32-78) and $29 \%(21-60)$ for the nonDC-Babyhaler and DC-Babyhaler respectively $(p<0.001)$. Amount of drug retained in the Nebuchamber was $46 \%$ (23-93), which was not significantly different from the amount retained in the nonDC-Babyhaler but significantly higher than in the DC-Babyhaler $(\mathrm{p}<0.001)$.

\section{Administration technique}

Table 1 shows the number of children that performed the administration technique correctly for each item on the checklist for both spacers. In one-third of the cases the
pMDI/spacer was not shaken correctly. A close fit of the face mask was observed in $73 \%$ of the cases for the Nebuchamber and in $92 \%$ for the Babyhaler. Additional observations for the Nebuchamber mask were that substantial pressure was used (pressing the nose down and causing flattening of the nose and whitening of the skin) or that parents folded their fingers around the edges to keep the face mask in place. Furthermore, the seal between the Nebuchamber mask and the face was easily interrupted by movements of the child. The suboptimal fit was clearly visible especially around the nose. Only half of the children managed to breath for $30 \mathrm{~s}$ through the spacer or managed to maintain the mask on the face. This showed that items requiring good cooperation (items 8,9 , and 10) during the administration procedure appeared to be difficult to achieve in this age group.

\section{Discussion}

In this study dose delivery and within-subject dose variability from a metal and a plastic spacer in children aged 5-26 months were compared. Furthermore, several factors that could affect dose delivery and dose variability in daily life were studied. Dose delivery from the spacers was on average one-third of the nominal dose with a wide range between the children. Dose delivery was lowest in the nonDC-Babyhaler and highest in the DC-Babyhaler. The dose variability, in daily life, in all of the tested spacers was found to be considerable. Dose variability in the nonDC-Babyhaler and the DC-Babyhaler were not significantly different and were lower than in the Nebuchamber. These findings are in contrast with other studies, in which the Nebuchamber with face mask delivered a similar dose as a detergent coated-Babyhaler [9], and a higher dose than other spacers $[5,14,15]$. However, these previous studies were performed in a laboratory setting, using controlled and standardized procedures, where one experienced person performed the administration. The present study, was performed in a daily life setting where the administration was done by parents. In this set-up the influence of factors such as cooperation and administration technique on

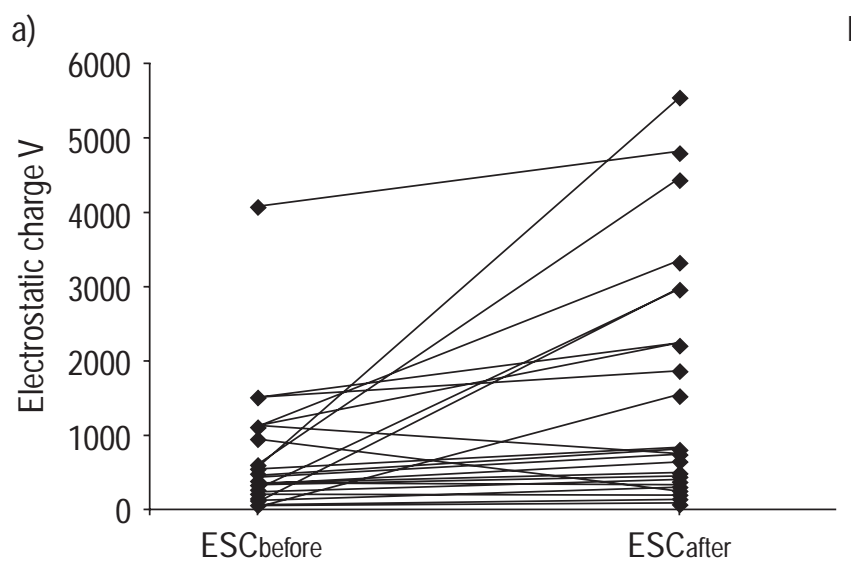

b)

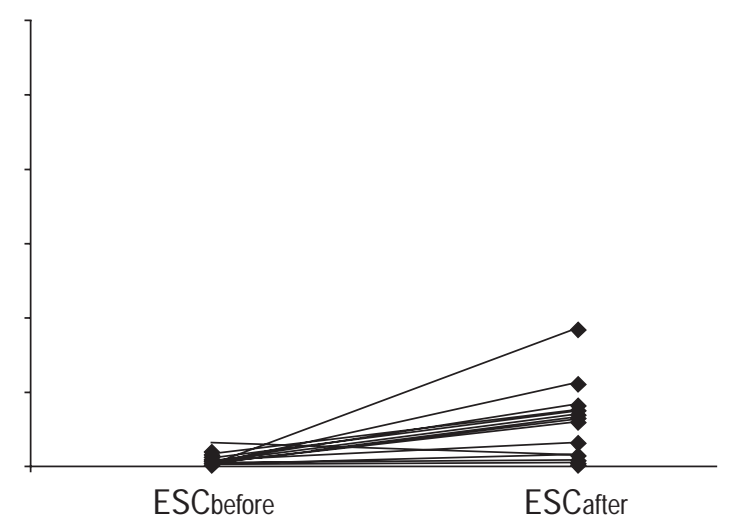

Fig. 4. - a) Electrostatic charge (V) for the non-detergent coated Babyhaler before (ESCbefore) and after (ESCafter) one week use for each child $(\mathrm{p}<0.001)$. Median ESCbefore: $370 \mathrm{~V}$ (range 0-4071); median ESCafter: $740 \mathrm{~V}$ (range 74-5550). b) Electrostatic charge (V) for the detergent coated Babyhaler before (ESCbefore) and after (ESCafter) one week use for each child (p<0.001). Median ESCbefore: 0 V (range 0-295); median ESCafter: 296 V (range 0-1850). ESCbefore and ESCafter for detergent coated Babyhaler compared with ESCbefore and ESCafter for non-detergent coated Babyhaler respectively: $\mathrm{p}<0.001$ for both. 
dose delivery and dose variability of spacers could be investigated.

For both the Nebuchamber and the Babyhaler, it was found that non-cooperation increased dose variability. For the Nebuchamber bad cooperation reduced dose delivery, but this correlation was not significantly present in the Babyhaler. It seems logical that the drug delivery of a spacer improves when a child is cooperative during the administration. However, the importance of cooperation for the administration of inhaled drugs in daily life has not been investigated previously. TAL et al. [4] found that lung deposition, in two infants, from a small volume plastic spacer was negligible when they were crying. Recently, it was shown that crying significantly reduces drug delivery to the lungs in infants [16]. The present study has clearly shown that cooperation is a major problem for aerosol therapy in young children in daily life. The video recordings showed that items requiring good cooperation during the administration procedure, i.e. quiet breathing, inhaling for $30 \mathrm{~s}$ and holding the face mask on the face for $30 \mathrm{~s}$ were achieved by only half of the children. It should be remarked that $30 \mathrm{~s}$ is quite a long period, which was obviously not achieved by many children. However, the optimal time in which for children to empty a spacer is not known. The authors chose a $30 \mathrm{~s}$ inhalation time after taking into account the small tidal volumes and irregular breathing patterns of children of this age [17]. Bad cooperation was scored by the parents in more than onefifth of all assessments. Even though the cooperation score was a subjective measure, scored by the parents on the diary cards, dose variability was found to be significantly higher when children were less cooperative. The findings emphasise the importance of stimulating good cooperation for optimal aerosol delivery from $\mathrm{pMDI} / \mathrm{spacers}$ in infants.

The seal of the face masks used might explain the discrepancies of the "daily life" findings with previous "laboratory" studies. The video-recordings showed that children were often struggling against the procedure, which is likely to affect the seal of the face mask. It seemed that in these young children the seal of the Nebuchamber face mask was more sensitive to movements than the Babyhaler face mask. The face mask of the Nebuchamber lost contact with the face more easily, which was visible on the video-recordings. However, the seal of the face mask was not objectively measured. The finding that dose delivery was correlated to the cooperation score for the Nebuchamber but not for the Babyhaler, supports the authors impression that cooperation plays a larger role in the dose delivery of the Nebuchamber. Additionally, it has been previously shown that the dose delivery for older and more cooperative children (17 months- 4 yrs) was higher and also dose variability was equal for the Nebuchamber when compared to the Babyhaler [6]. The results may be explained by the difference in design of the Nebuchamber mask and the Babyhaler mask. The Nebuchamber mask is pre-shaped to the facial contours, but did not seem to fit on each face. This mask was designed to minimize the dead space of the inhalation system. The Babyhaler mask has a larger dead space, but is round and made of a more flexible material than the Nebuchamber. With this face mask it seemed easier to achieve a tight fit in these young (uncooperative) children. Recently, AmIRAV and NewHOUSE [18] found that ventilation through a pneumotachograph was better and less variable with a Babyhaler face mask than with a Nebuchamber face mask, when tested in children $<5$ yrs of age. It has been shown before that holding a face mask $2 \mathrm{~cm}$ from the face substantially reduces the dose delivered [3]. Based on these arguments it is suspected that the relatively high dose variability of the Nebuchamber can be explained by a suboptimal fit of its face mask. The authors hypothesize that aerosol delivery of the Nebuchamber for infants can be improved by an improved design of the face mask.

The results of the checklist for administration technique showed that even when instructions were given repeatedly, many mistakes were still made. Similar findings were found in another study in older children where $14-26 \%$ of children, depending on the type of spacer used, failed to demonstrate critical skills for using a spacer efficiently [19]. Consistent differences between children in administration techniques, breathing patterns and cooperation can explain why children with a low dose delivery or high dose variability in one spacer tended to show this in the other spacers also. It has been shown that patient-dependent factors such as tidal volume [3] and inhalation flow [20] are determinants for drug delivery from spacers, which can vary the dose delivered remarkably. The results emphasize the need for regular evaluation of administration technique while a child is treated with inhaled drugs by $\mathrm{pMDI} / \mathrm{spacer}$.

Plastic spacers accumulate ESC, which decreases the dose delivered [7,8]. The present study showed that detergent coating of the spacer was effective in reducing ESC, although its effect diminished over a one week period of daily use. Reducing ESC resulted in a higher dose delivery and less drug retained in the spacer. Priming of the spacer, during one week use, did not decrease ESC. The effect of priming was probably too small to compensate for other, not studied, factors that increase ESC. The influence of ESC on dose variability was investigated. Dose variability in the nonDC-Babyhaler and the DC-Babyhaler were comparable, and the dose variability was higher in the Nebuchamber, in which ESC is absent. Furthermore, in an earlier study carried out by the authors, dose variability was the same in the Nebuchamber and in the nonDCBabyhaler in children 1-4 yrs of age [6]. In the present study, it was found that ESC is not a potential source for dose variability in the plastic Babyhaler. Whether this is applicable to all plastic spacers needs to be investigated further.

No correlation between age and dose delivery or dose variability was found. In previous studies dose delivery from a Nebuchamber and a Babyhaler were also age independent $[5,6,9]$. Previously, it was shown that dose variability was inversely related to age in children $<5$ yrs of age [6]. The small range in age might explain why no age dependent dose variability was found in the present study. Also the fact that cooperation played a larger role in this age group than in the group $<5$ yrs of age, could have masked a small age effect.

Caution must be taken when interpreting filter studies, as was the case with the present study, with regard to clinical efficacy and lung deposition. The doses found on the filters is the amount of aerosol delivered to the mouth. It does not give any information on where in the respiratory tract the drug will be delivered. However, the filter method was sufficient to answer the authors questions with regards to the reproducibility of aerosol delivery from pMDI/ 
spacers in daily life. Further research is needed to study the therapeutic implications of the present findings.

To conclude, considerable within-subject dose variability was found when spacers were used at home by infants aged 5-26 months. High dose variability means that the day-to-day dose delivered from spacers is unpredictable. Reducing electrostatic charge by detergent coating of a spacer was effective for increasing dose delivery but had no influence on the dose variability. Hence, electrostatic charge appeared not to be important for dose variability in the spacers studied. Dose variability was highest in the Nebuchamber and it was speculated that this was caused by a suboptimal fit of the face mask in this age group. Children with good cooperation during the administration procedure had a lower dose variability in all the spacers. The results of the present study show the importance of performing studies in the "daily life" setting. Whether or not the training of parents and their children and the evaluation of cooperation during the administration of inhaled drugs leads to more effective aerosol treatment, remains to be shown.

\begin{abstract}
Acknowledgements. The authors would like to thank B. Ponsioen and R. Schornagel for the recruitment of patients, L. Scheek and E van der Wiel for technical assistance, E. Berg and C. Rossborg for technical advice and providing analytical equipment. They would also like to thank P.J.F.M. Merkus, S. Suelmann, M. Taapken, A. Lok, and E. van der Wiel for scoring the videos and the parents and children for their participation in the study.
\end{abstract}

\section{References}

1. Agertoft L, Pedersen S. Influence of spacer device on drug delivery to young children with asthma. Arch Dis Child 1994; 71: 217-219.

2. Barry PW, O'Callaghan C. Inhalational drug delivery from seven different spacer devices. Thorax 1996; 51: 835-840.

3. Everard ML, Clark AR, Milner AD. Drug delivery from holding chambers with attached face mask. Arch Dis Child 1992; 67: 580-585.

4. Tal A, Golan H, Grauer N, Aviram M, Albin D, Quastel MR. Deposition pattern of radiolabeled salbutamol inhaled from a metered-dose inhaler by means of a spacer with mask in young children with airway obstruction. $J$ Pediatr 1996; 128: 479-484.

5. Bisgaard H, Anhoj J, Klug B, Berg E. A non-electrostatic spacer for aerosol delivery. Arch Dis Child 1995; 73: 226-230.
6. Janssens HM, Devadason SG, Hop WCJ, LeSouef PN, Jongste de JC, Tiddens HAWM. Variability of aerosol delivery via spacer devices in young asthmatic children in daily life. Eur Respir J 1999; 13: 787-791.

7. Barry PW, O'Callaghan C. The effect of delay, multiple actuations and spacer static charge on the in vitro delivery of budesonide from the Nebuhaler. Br J Clin Pharmacol 1995; 40: 76-78.

8. Wildhaber JH, Devadason SG, Hayden MJ, et al. Electrostatic charge on a plastic spacer device influences the delivery of salbutamol. Eur Respir J 1996; 9: 1943-1946.

9. Wildhaber JH, Devadason SG, Hayden MJ, Eber E, Summers QA, LeSouef PN. Aerosol delivery to wheezy infants: Comparison between a nebulizer and two small volume spacers. Pediatr Pulmonol 1997; 23: 212-216.

10. Kraemer R, Birrer P, Modelska K, Aebischer CC, Schoni $\mathrm{MH}$. A new baby-spacer device for aerosolized bronchodilator administration in infants with bronchopulmonary disease. Eur J Pediatr 1992; 151: 57-60.

11. Berg E. In vitro properties of pressurized metered dose inhalers with and without spacer devices. $J$ Aerosol Med 1995; 8: S3-S10.

12. Cyr T, Graham SJ, Li RKY, Lovering EG. Low first-spray drug content in albuterol metered-dose inhalers. Pharm Res 1991; 8: 658-660.

13. Stocks J, Marchal F, Kraemer R, Gutkowski P, Yishay EB, Godfrey S. Plethysmographic assessment of functional residual capacity and airway resistance. $I n$ : Stocks J, Sly P, Tepper R, Morgan W, eds. Infant respiratory function testing. New York: Wiley-Liss, Inc., 1996; p. 232.

14. Berg E, Madsen J, Bisgaard H. In vitro performance of three combinations of spacers and pressurized metered dose inhalers for treatment in children. Eur Respir J 1998; 12: 472-476.

15. Kenyon CJ, Thorsson L, Borgstrom L, Newman SP. The effects of static charge in spacer devices on glucocorticosteroid aerosol deposition in asthmatic patients. Eur Respir J 1998; 11: 606-610.

16. Iles R, Lister P, Edmunds AT. Crying significantly reduces absorption of aerosolised drug in infants. Arch Dis Child 1999; 81: 163-165.

17. Bisgaard H. Patient-related factors in nebulized drug delivery to children. Eur Respir Rev 1997; 7: 376-377.

18. Amirav I, Newhouse M. Delivery of aerosols to children with MDI and holding chambers (MHC) is critically dependent on the face mask seal. Am J Respir Crit Care Med 1999; 159: A142.

19. Boccuti L, Celano M, Geller RJ, Phillips KM. Development of a scale to measure children's metered-dose inhaler and spacer technique. Ann Allergy Asthma Immunol 1996; 77: 217-221.

20. Newman SP. A comparison of lung deposition patterns between different asthma inhalers. J Aerosol Med 1995; 8: S21-S26. 